\title{
Editorial Science: evidence based but freedom of ideas
}

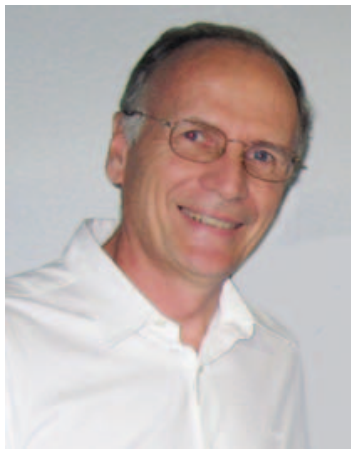

Already at the end of the nineteenth century Claude Bernard made a very explicit statement: "When in medicine, a practitioner bases his action on his inspiration or intuition, he is outside of science, providing a perfect example of this archaic and fanciful medicine, open to the whims of a more or less ignoring inspired".

The current medical world seems to have rediscovered Claude Bernard. The rules and virtues of the "experimental method" led to the use of reproducible therapeutic methods and less invasive ones. "Evidence-based medicine (EBM)" aims to write new tables of the law of therapy. Are they mathematical laws? Léonardo da Vinci foresaw this phenomenon: "The universe hides under random appearances of strictly mathematical rules". To know and comply with these rules is the foundation of our science. But are we sufficiently erudite to do so? Even if the thousand-year-old progressive conquest of the rational at the expense of the irrational characterizes our civilization, a number of rules still remain concealed to us, particularly our masticatory microcosm. Today, in this field, a scholastic concept of EBM is a component utopia. Moreover, it is likely to pave the way for a new form of scholastics.

\section{Utopia}

Currently, to think that we conduct treatment solely according to the principles of EBM is utopia. In our field, because of the immense difficulties (technical and institutional) encountered by clinical research, validated scientific knowledge is rare, often simplistic, and sometimes contestable. Moreover, the clinical choices of today are largely founded on weak evidence or on opinions which appear to point out to the best direction, or the experience of old practitioner.

\section{Ostracism}

Copernicus (XVI century), who finally chose not to publish his work during his lifetime wrote "The scientist is free to formulate assumptions even if they are absurd in comparison with the theologians in charge of scientific power". Claude Bernard noticed that "systematic reasoning or scholastics is only one proof of ignorance; it is natural for the inexperienced and arrogant spirit”.
In its clarity and rigor, deductive reasoning at first appears to be the key instrument of scientific progress because it is the only acceptable method of a comprehensive science. However, Louis de Broglie insists that, in an incomplete science which is still progressing, inductive reasoning is the real source of scientific progress. Even Einstein minimizes the role of experience in the origin of discovery and assigns high value to intuition in science. To him experimentation, or possibly its mathematical translation, has no other purpose than allowing the verificationa posteriori- of the principle of a "simple idea". Thus follows the postulate that the idea itself shows the way, which will be then be expressed by rigorous experimentation.

\section{The necessity of reason and the essential freedom of creativity}

In the interest of evidence the scientist adhered to his limited world of analysis, deduction, and the risk of locking himself if not drowning in his utopia. This attitude occasionally led him to reinvent the wire for cutting butter. Logic remains sterile unless it is fertilized by intuition. We need to promote the freedom of creativity. Championing the cause of proof and scientific evidence might close the door to intuition and, consequently, the door to scientific journals, conferences, universities, and spirits.

For Diderot (XVI century) "there are no walls or hierarchies within knowledge; there are only artificial barriers built by ignorance, contempt and social arbitrariness. The path of knowledge is marked by the necessity of reason and the essential freedom of imagination".

The learned creators of science lessons are introspective themselves on the reality of their own inventions, and the great priests of the irrational are uncertain about the foundations of their belief.

It is incumbent upon the leaders of our field to promote, from their "ivory tower", the expression of new ideas while adhering to a simple principle: all opinions are lawful from the time of their expression; this is identified as a personal idea and the opposite opinion should also be heard immediately. Freedom contains always risk factors, but obviously, sharks will benefit from this approach, but their actions would be negligible compared to the possibility of leaving some shining bright ideas.

Nothing is more important than the exchange ideas even if some of them are false.

Jean-Daniel Orthlieb

E-mail: orth.jd@numericable.fr

\section{Reference}

[1] Bernard C. Introduction à l'étude de la médecine expérimentale, 1865. Paris (Reedition. Champs, Flammarion, Paris ISBN 2080811371). 